\title{
The Influence of Knowledge Sharing on Organizational Performance and the Countermeasures
}

\author{
Hong JI \\ Jiangxi Normal University Science and Technology \\ College \\ Nanchang, China \\ jxsdjh@vip.sina.com
}

\author{
Shu-yuan ZOU \\ Jiangxi Normal University Business College \\ Nanchang, China
}

\begin{abstract}
The most important part of knowledge management is knowledge sharing, which is the prerequisite for the process of knowledge collection, transfer and reconstruction. Knowledge sharing among employees within an organization is an important means for organizations to gain a competitive advantage. This paper analyzes the connotation, the basic way and the factors that affect the knowledge sharing, then puts forward the knowledge sharing strategy within the organization, and then analyzes the positive and negative effects of knowledge sharing on organizational performance. Finally, to respond to the negative impact of the organization to respond.
\end{abstract}

Keywords-knowledge sharing; sharing strategy; influence; organizational performance

\section{INTRODUCTION}

In the era of knowledge economy, knowledge becomes the key to winning enterprise. The most important part of knowledge management is knowledge sharing, which is the prerequisite for the process of knowledge collection, transfer and recycling. The knowledge sharing behavior among employees within the organization has a strong effect on the process of post-knowledge collection and transfer. Personal knowledge, if not shared, can only become a personal wealth, can not constitute the enterprise's resources, and once the personal knowledge to participate in knowledge sharing, you can become internal knowledge of the organization, which constitute the enterprise's resources. Can enhance the competitiveness, cultivate competitive advantage, and expand the market share of enterprises. Therefore, if the individual employees of the intellectual value of the full play out, it must be fully shared.

\section{KNOWLEDGE SHARING THE BASIC WAY AND INFLUENCING}

\section{FACTORS}

\section{A. The Connotation of Knowledge Sharing}

Before the scholars for their own knowledge sharing research, different scholars for knowledge sharing different definitions, these definitions are mainly summarized as two categories. A definition of knowledge sharing is a kind of exchange process, with a person's knowledge and experience to communicate and exchange with another person, so that two people share this knowledge. Another definition defines knowledge sharing as a unilateral transformation process, and a person transforms his knowledge into knowledge that is easy for others to understand and absorb. Regardless of the way in which knowledge sharing is defined, the process of knowledge sharing must be knowledge owners and knowledge recipients, and one of the factors that lacks knowledge sharing can not be done. Knowledge sharing requires not only the knowledge owner to transmit the knowledge to the recipient, but also the recipient must internalize the acquired knowledge into his own knowledge. Based on this, this paper believes that knowledge sharing refers to the enterprise, government or organization of internal staff to communicate their own knowledge and exchange, so that their knowledge into the organizational level.

\section{B. The Basic Way of Knowledge Sharing}

The main body of knowledge sharing can be divided into three levels: individual, team and organization. The main body is different, and the way of knowledge sharing will be different. Specifically [1]: the most common way to share knowledge at the individual level is to communicate directly, and some employees want to be able to communicate and form a document. Personalized approach, this approach is the most direct and simple way, that is, through direct communication between people to carry out knowledge sharing, in this relatively fast way, to improve the efficiency of the organization.

Organizational level of knowledge sharing is the organization to use their own management structure and technology to personal knowledge into easy to understand that explicit knowledge, is to encode the knowledge, making it a database to facilitate the use of internal staff. This way of communication is defined by the scholar as a method of information coding.

\section{Influencing Factors of Knowledge Sharing}

Organizational culture. The influence of culture on knowledge sharing among enterprises is mainly manifested in two aspects: not suitable corporate culture will hinder knowledge sharing in the enterprise. For example, in the influence of egoism culture, knowledge owners worry about their knowledge to others will waste their time, also worry about sharing their knowledge with others will lose their competitive advantage, therefore is not willing to waste their time with other employees to share knowledge. The influence of the organizational culture emphasizes the interests of small groups under various departments because of too much emphasis on their goals and interests, while ignoring the organization's goals and interests, each department will carry 
out knowledge sharing in their own departments, it is difficult to cross departmental boundaries of knowledge sharing. A good cultural atmosphere can regulate, condense, motivate and reinforce people's behavior, thus effectively promoting the smooth progress of knowledge sharing. Mutual trust culture can motivate employees in a harmonious atmosphere, contribute to the communication between team members, staff exchanges will promote employee knowledge sharing, while employees are not necessarily the exchange of content knowledge, but the mechanism of this exchange is to make them have a common solution to the problem it will, when there is a problem, in their own can not solve the case will seek help from others, would produce knowledge sharing. In the learning organizational culture, employees have a strong willingness to learn, so they are willing to learn knowledge from others, and promote knowledge sharing in the process of learning from each other.

Organization structure. Organization is a complex system, and it is generally believed that organizational centralization and normalization are the two most important characteristics of an organization [2]. From the point of view of organizational structure, the centralization and decentralization of organization mean that the decision-making power of an organization is mainly concentrated in the upper or the opposite. Centralization refers to the organizational decision-making and control, so the decision is mainly in the implementation of superior sharing, thus impeding knowledge in the organization on the contrary, the appropriate decentralization can promote knowledge sharing in the organization, the dispersion will lead to more freedom of speech power, contribute to the formation of employees to actively participate in the construction of knowledge environment because, no one can have all the knowledge needed to make decisions, we must make the decision-making knowledge set maximum through knowledge sharing within an organization to make the best decision. Organizational formalization refers to the level of standardization and written statements of the organization's rules and procedures. It represents the extent to which an organization applies rules. When strict rules are applied to the organization, new ideas can easily be limited. In the traditional organizational structure, the management level is many, the grade idea is strict, in these organizations the circulation knowledge is very many, with the universal knowledge primarily, therefore has not been strong to the knowledge sharing request. Knowledge can only strictly follow the sharing mechanism from top to bottom, or from bottom to top, and leapfrog knowledge sharing is almost impossible. The dissemination of information channels leads to information asymmetry between the upper and lower levels, and slow the speed of transmission of knowledge, knowledge transfer through the layers, may be reduced or even distorted information, recession or information distortion phenomenon is very serious. There is a lack of cooperation and communication among employees in a hierarchy and a hierarchy of too many organizations. Therefore, there is a lack of atmosphere for learning and exploring problems. In the organizational structure of the department level, members of the organization of work tasks are scheduled according to the manager's intention to work, they just want to do your thing, do not consider providing knowledge to help others, but also to attend to knowledge sharing. Therefore, the traditional hierarchical organizational structure makes it difficult for the organization members to break through the constraints of their jobs, and it is difficult to communicate and exchange, and the knowledge sharing in the organization can not be achieved. Different from the traditional functional organization structure, the modern organizational structure has become a trend of flattening, multi polarization and network development.

Information technology. Knowledge sharing is based on the data management technology and information management technology, aiming at some special function, can help the knowledge sharing process of knowledge staff and activities of the technical characteristics of developed knowledge. Knowledge sharing in organizations is largely limited by time and space. But as time goes by, it becomes more and more difficult to find the right knowledge in the organization memory, especially the long time knowledge [3]. At the same time, the development of the organization is no longer limited to the local, but distributed all over the world. This space distance leads to the lack of communication and the high cost of knowledge sharing and the difficulty of sharing. The knowledge in the enterprise brings together all kinds of information of employees and departments, so it has many kinds, large quantities, and knowledge is hidden in a large amount of information. Without the support of information technology, the knowledge demander would have to pay a lot of effort to search for the knowledge they need, and sometimes even do not know where to find the knowledge they need. Knowledge sharing technology can help people to limit the number and quality of time, space and knowledge, thus providing strong technical support for effective realization of knowledge sharing. At present, the common knowledge sharing technologies are mostly based on computer and Internet technology, such as knowledge base, LAN, knowledge map, etc... For example organization by LAN can put all departments and organizations around the staff together, through the LAN rapid dissemination of knowledge, sharing new ideas, speed up the organization between the various departments of communication; employees can also through the LAN faster and better retrieval organization resources, improve work performance. Enterprises can effectively use the computer network and communication system to establish a convenient knowledge base for employees to search for the staff to search for the necessary knowledge.

\section{BASIC IDEAS OF CONSTRUCTING KNOWLEDGE SHARING}

\section{MECHANISM IN THREE ORGANIZATIONS}

Because of the factors that affect knowledge sharing, organizations should develop appropriate mechanisms for them to maximize the value of knowledge sharing within the organization.

\section{A. To Actively Reduce the Knowledge of Employees Within the Organization Differences}

Taking into account the individual psychological factors, the organization should be in many ways to reduce the difference between the knowledge of employees. Organizations in the recruitment of staff, the candidates should be the knowledge of the most part of the assessment. Personnel 
working within the organization should also be regularly engaged to work with their own positions. As far as possible so that all employees within the organization to understand and master the Organization of all the necessary knowledge and experience. In order to reduce the difference in knowledge reserves among employees, organizations can use incentives to reward those employees who share knowledge sharing and punish those who deliberately do not share knowledge for their own interests.

\section{B. Employees to establish a relationship between mutual trust}

As an organization to be able to drive the staff for their work, the organization in the formation of their own culture, to the staff to pass a knowledge-sharing culture. Trust between employees is the premise of knowledge sharing. In many shared knowledge, not every knowledge is needed by the organization, which requires the organization to choose according to itself. Organizations need to have a clear understanding of their long-term strategic goals, and then the organization's business processes and core activities to analyze the need to determine the need to share knowledge.

\section{THE POSITIVE IMPACT OF KNOWLEDGE SHARING ON}

\section{ORGANIZATIONAL PERFORMANCE}

Knowledge sharing is extremely beneficial to the organization's productivity and communication, it can help organizations reduce duplication of effort and avoid the loss of knowledge among employees in an organization. Therefore, most organizations advocate knowledge sharing and inter-organizational knowledge within an organization shared. Although knowledge sharing has a significant positive effect on the efficiency of the organization, knowledge sharing also has its negative impact on the organization. The positive impact of knowledge sharing on organizational performance is:

\section{A. To Improve the Organization's Core Competitiveness in the Market}

An organization if the internal staff can be selflessly their own tacit knowledge directly with other employees exchange, and the organization has a sound knowledge sharing system, then the organization can use their own information technology to focus on the formation of personal knowledge at the organizational level, It is easier for employees to carry out knowledge innovation in this process, and knowledge innovation has a guiding role in practical innovation and technological innovation. And innovation is the soul of an organization, is the organization continue to grow and develop inexhaustible motive force. Organizations have innovative knowledge and production technology will form their own advantages, the organization will be bigger and bigger will form economies of scale, so that the cost of production products will be lower than similar organizations, competitive advantage. Of course, the knowledge sharing process to be affected by a factor, that is, personal mobility. If the organization does not have a reasonable and perfect knowledge sharing mechanism, it will make the excellent staff feel that the income is unreasonable, therefore, the idea of leaving the organization. The departure of excellent employees is undoubtedly detrimental to the organization [4].

\section{B. Optimize Knowledge Resource Allocation}

Scholars have done a lot of research on knowledge sharing in organizational knowledge resource allocation. In a perfectly competitive market, resources can be optimally configured because resource prices are entirely determined by market supply and demand, are not subject to government intervention, and there is no interference with information asymmetry. Although knowledge is a special resource - different from the physical resources, but its configuration to achieve the best, but also follow the same principle. In the organization, knowledge sharing is to break the knowledge asymmetry between the individual and the individual, to break the knowledge barrier, and to form the common knowledge of all the employees in the organization. In this way, knowledge resources can be optimally configured. The effective allocation of knowledge resources is the organization of efficient guarantee.

\section{Reduce Organizational Risk}

In the above, we refer to personal mobility, and if employees feel that they are treated unfairly, they will have the idea of leaving the organization. Often, excellent employees with a lot of expertise, certain professional skills, and years of work experience are more likely to feel that they are disproportionate to pay their earnings, and they choose organizations that can achieve their own value and profitability. And the departure of outstanding employees is not just a talent loss, his departure also took away their own hidden knowledge, work experience, and even the original organization of information and old customers. As a result, the loss of excellent employees is a heavy blow to the organization. Knowledge sharing is to make those excellent employees and professional and technical personnel to their tacit knowledge dedicated to the organization, the organization uses knowledge coding stored in the database, to facilitate other employees to learn and imitate [5]. The greatest degree of reduction of organizational risk.

\section{Efficient Access to Knowledge}

Knowledge sharing is certainly not limited to the Organization, but it is also important to share knowledge outside the organization. However, the knowledge sharing outside the organization is relatively transparent, and each organization can learn and absorb knowledge, which has little effect on the formation of its own advantages. To form a sustained core competitive advantage, we must effectively carry out knowledge sharing within the organization. This knowledge is not easy for external organizations to learn, more effective. 


\section{THE NEGATIVE IMPACT OF KNOWLEDGE SHARING ON}

\section{ORGANIZATIONAL PERFORMANCE}

\section{A. Increase Organizational Risk}

Unlimited knowledge sharing increases organizational risk. Knowledge sharing is good, but if unrestricted in the organization to share, it is easy to make the knowledge flow out of the organization, and even the core technology and confidential information outflow. The organization can not guarantee that every employee can work for the organization to retire, there will certainly be employees to switch jobs, and there will be employees in the interests of the temptation to the organization of important information to the competitors. And the organization's core competitive advantage once owned by other organizations have a direct threat to the survival of the organization. Therefore, we must not keep the knowledge sharing.

\section{B. Breeding "Free Rider" Phenomenon}

The so-called "free ride" is the staff to borrow the platform provided by the organization to absorb their own knowledge, but their expertise is not shared with other employees within the organization. "Free ride" phenomenon is due to personal egoism and knowledge of the super externalities. Organizations advocate knowledge sharing is based on the strategic objectives of the organization, and as the organization's smallest unit of individuals also have their own career development goals, the goal is to maximize the interests of the individual as the premise, often inconsistent with the organizational goals. Relative to the interests of enterprises, employees will be more concerned about their own interests. Minimize the cost of acquiring knowledge. This produces a "free ride" phenomenon. Once this phenomenon breeds, it will quickly spread from individual behavior to every employee. When most of the employees are guided by their own interests, the organization is not a group with a common strategic goal, but a fragmented individual has seriously weakened the organization's cohesion.

\section{ENTERPRISES TO OVERCOME THE NEGATIVE IMPACT OF}

\section{KNOWLEDGE SHARING ON ORGANIZATIONAL PERFORMANCE}

"Free ride" phenomenon has greatly dampened the enthusiasm of the staff work, but also to a certain extent, affected the organization cohesion. Therefore, the organization should take effective measures to eliminate this phenomenon.

\section{A. Establish and Improve the Incentive Mechanism for Knowledge Sharing}

As the reality is self-serving, to employees consciously share their knowledge and other employees, it is necessary to establish incentives to promote employee knowledge sharing. When employees share the knowledge of the interests of the organization, the organization should be timely to the staff to praise, and sometimes can give appropriate incentives. This will enhance the enthusiasm of employees to share knowledge, and more willing to share knowledge with other employees. This incentive mechanism must be established to follow the principle of fairness as a prerequisite, but to be fair and reasonable there must be a sound job performance evaluation system. In strict accordance with this system to reward and punishment of employees, for those who selfless dedication of their knowledge, willing to share knowledge and experience with others employees, to vigorously praise the "free rider" staff to give punishment. Based on the amount of knowledge and value of staff to share, so that a fair and reasonable evaluation of staff work ability, can effectively reduce the negative emotions of staff work [6].

\section{B. To Establish the Concept of the Interests of the Community}

Team spirit is particularly important in which organization, the team spirit of the training is mainly between employees within the organization, between employees and their superiors and between the superior and the mutual trust. Trust is the basis of teamwork, but also employees and employees to share knowledge of a strong guarantee. When employees in the organization have the same goal, and there is a strong sense of dependence and trust between each other, it will cultivate the sense of belonging to the organization. The sense of belonging makes the sharing of knowledge among employees more smoothly, effectively reduces the information asymmetry within the organization, weakened the staff's self-serving thinking, "free ride" problem is solved. Organizations can also study the herd mentality, and then guide the staff of the idea, so that employees are proud of knowledge sharing.

\section{ACKNOWLEDGMENT}

With the advent of the era of knowledge economy, knowledge has gradually become a key resource for economic growth, social development and business growth. The competitive advantage of future enterprises will come mainly from the ability to gather, develop and combine various knowledge resources, and knowledge sharing provides a way for enterprises to develop knowledge resources and create new resources adapted to market changes. Knowledge sharing can promote knowledge innovation and Dissemination, to achieve the constant value of knowledge, and in the growing disruptive changes in the environment to enhance the organization's organizational resilience and competitiveness.

\section{REFERENCES}

[1] Wang Yang. Research on the relationship between communication, knowledge sharing and employee performance. D. University of South China, vol. 26, pp.147-151, 2016.

[2] Chen Tao, Zhu Zhiming, Wang Tienan. Organizational memory, knowledge sharing and firm performance. J. research and development management, vol.3, pp. 43-55, 2014.

[3] Chen Tao. Research on the influence of organizational memory and knowledge sharing on firm performance. D. Harbin Institute of Technology, vol44, pp. 87-92, 2015.

[4] $\mathrm{Xu}$ Liang. Research on the relationship between team knowledge sharing and industrial design performance .D. Dongbei University of Finance and Economics, vol. 34, pp. 312-316, 2016.

[5] Fan Zhiping, Sun Yonghong. A survey of knowledge sharing. Journal of. J. management, vol. 3, pp. 371-379, 2010.

[6] Wang Lijie. Research on the relationship between tacit knowledge sharing and organizational performance based on organizational culture.D. Chongqing University, vol. 18, pp. 122-126, 2015. 